\title{
HEGEL, EL DINERO Y LA "ECONOMÍA POLÍTICA"
}

Rafael González Díaz y

Carlos J. McCadden M.*

RESUMEN: A Hegel se le acusa de ser un pensador totalitario, un abogado del "estatismo" y un "enemigo de la libertad". Se supone que no tiene un pensamiento económico y que si logró hacer algunos esbozos al respecto, deben ser ignorados. Una exégesis rigurosa de las obras de Hegel no permite que se le atribuya el título de pensador totalitario. Al contrario, Hegel es un pensador liberal. No solo estudió la economía política de James Steuart (1707-1780) y de Adam Smith (1723-1790), sino que dedicó una parte de su reflexión a temas económicos como el "dinero", el "sistema de necesidades" y la "sociedad civil". Para Hegel, el desarrollo de la libertad individual consolidó al "dinero" como medio de cambio universal y este, al mismo tiempo, posibilitó unas relaciones más justas entre los hombres.

\section{yos \\ HEGEL, MONEY AND "POLITICAL ECONOMY"}

ABSTRACT: Hegel is accused of being a totalitarian thinker, an advocate of "statism" and an "enemy of freedom". It is assumed that he does not have an economic thought and that if he managed to make some sketches about them they should be ignored. A rigorous exegesis of Hegel's works does not allow the title of totalitarian thinker to be attributed to him. On the contrary, Hegel is a liberal thinker. He not only studied the political economy of James Steuart (1707-1780) and Adam Smith (1723-1790), but devoted a part of his reflection to economic issues such as "money", "needs system" and "civil society". For Hegel, the development of individual freedom consolidated "money" as means of universal change and this, at the same time, made possible more just relations among men.

*Ambos autores son profesores del Departamento Académico de Estudios Generales, ITAM. 
Se prohíbe su reproducción total o parcial por cualquier medio, incluido electrónico, sin permiso previo y por escrito de los editores.

PALABRAS CLAVE: filosofía de la economía, filosofía política hegeliana, liberalismo, teoría del valor.

KEY WORDS: Hegelian political philosophy, liberalism, philosophy of economics, theory of value.

RECEPCIÓN: 7 de enero de 2019.

APROBACIÓN: 18 de febrero de 2019.

DoI: $10.5347 / 01856383.0129 .000294416$

Estudios 129, pp. 79-111, vol. XVII, verano 2019. 


\title{
HEGEL, EL DINERO Y LA "ECONOMÍA POLÍTICA"
}

\section{La "economía política” en Hegel}

\begin{abstract}
A Hegel se le acusa de ser un pensador totalitario, un enemigo de la libertad social, económica y política que subordina a la persona a los confines de un "sistema cerrado". Además, a su filosofía se le responsabiliza del nacimiento de todos los regímenes autoritarios del siglo XX. ${ }^{1}$ Al respecto dice Karl Popper:

El hegelianismo constituye el renacimiento del tribalismo. Puede apreciarse la significación histórica de Hegel en el hecho de que este representa el "eslabón perdido", por así decirlo, entre Platón y la forma moderna del totalitarismo. La mayoría de los totalitarios modernos no tienen la menor conciencia de qué ideas se remontan hasta Platón. En su mayor parte, conocen su deuda con Hegel y todos ellos han sido educados en la densa atmósfera hegeliana. Así, se les ha enseñado a adorar al Estado, la historia y la nación. ${ }^{2}$
\end{abstract}

En el centro de estas críticas está el prejuicio de que Hegel no tiene un pensamiento económico y que si logró hacer algunos esbozos, no tienen importancia porque al final su aportación derivó en la izquierda hegeliana marxista o la derecha totalitaria del siglo XX.

${ }^{1}$ Cfr. Dalmacio Negro Pavón, "Hegel y el totalitarismo", Revista de Estudios Políticos, 200/201 (1975), pp. 101-137.

${ }^{2}$ Karl Popper, La sociedad abierta y sus enemigos, 2010, Barcelona, Paidós, p. 248. 
A pesar de todo esto, el pensamiento económico de Hegel ha sido objeto de un prolongado debate académico. ${ }^{3}$ Una de las interpretaciones más difundidas dice que Hegel es un precursor de las concepciones de Marx, y que sus nociones de trabajo (Arbeit), propiedad (Eigentum), valor (Wert), capital (Kapital), dialéctica (Dialektik), enajenación (Entfremdung), etc., son el anuncio profético de las tesis que posteriormente sostendría Marx. ${ }^{4}$ Hegel sería la "versión idealista" de Marx y este la verdadera culminación del hegelianismo. A la filosofía de Hegel como precursora del marxismo solo habría que invertirla para darle un sentido materialista.

Si bien la interpretación marxista de Hegel impide la comprensión de la originalidad del pensamiento económico hegeliano y los rasgos definitorios de su "liberalismo", no obstante tiene el mérito histórico de haber "rehabilitado" el estudio de Hegel al tomarlo en serio como un riguroso pensador en cuestiones económicas y sociales. ${ }^{5}$ En palabras de Steve Smith: "el repunte del marxismo fue, a lo sumo, una condición necesaria aunque insuficiente para una adecuada interpretación de Hegel". 6 La interpretación marxista de Hegel llega al extremo de querer encontrar a Marx en todo el sistema hegeliano proponiendo paralelismos arriesgados e inverosímiles, como si Marx estuviera ya encriptado en Hegel. Así, por ejemplo, se sostiene que la "lógica hegeliana" es el dinero del Espíritu. ${ }^{7}$

${ }^{3}$ Cfr. Karl Marx, Nationalökonomie und Philosophie, en S. Landshut (ed.), Karl Marx. Die Frühschriften, 1971, Stuttgart, Kröner, pp. 225-316; Paul Chamley, "Les origines de la pensée économique de Hegel", Hegel Studien, 3 (1965); Paul Chamley, "La doctrine économique de Hegel d'après les notes de cours de Berlin", en D. Henrich y R.-P. Horstmann (comps.), Hegels Philosophie des Rechts, 1982, Stuttgart; James Henderson et al. (comps.), “Adam Smith's influence on Hegel's philosophical writings", Journal of the History of Economic, 13 (1991).

${ }^{4} C f$ r. Josu Zabaleta Imaz, "Dinero como lo singular universal. Una lectura del concepto de dinero en Marx desde la categoría de la medida de Hegel”, Bajo palabra, 5 (2010), pp. 17-30.

${ }^{5}$ Cfr. Steven Smith, Hegel y el liberalismo político, 2002, México, Ediciones Coyoacán, trad. de Eric Herrán, pp. 13-16. El ejemplo que presenta el autor es el trabajo de Alexandre Kojève, una interpretación marxista de Hegel que condicionó a toda una generación.

${ }^{6}$ Loc. cit.

${ }^{7}$ Cfr. Germán D. Castiglioni, “¿En qué sentido es la Lógica de Hegel el dinero del espíritu? Interpretación del sistema hegeliano desde la génesis del dinero en El capital de Marx", Tópicos, 31 (2016), pp. 22-41. 
Para otros autores, la filosofía de Hegel es el fundamento del "comunitarismo" y de todas las posturas críticas a la teoría liberal y su pretendido universalismo. Esto sería particularmente verdadero frente al concepto de individuo como realidad abstracta y ahistórica que es un postulado central del liberalismo clásico y que estos autores consideran generalmente una devaluación de la cultura. El ejemplo paradigmático de esas lecturas comunitaristas de Hegel sería la realizada por Charles Taylor ${ }^{8}$ (1931-), que se inserta en el debate contemporáneo en torno al relativismo y el multiculturalismo. ${ }^{9}$

En el otro extremo estarían los autores y las interpretaciones de Hegel que sostienen que su pensamiento económico no es otra cosa que la "reelaboración" de los postulados del liberalismo clásico. ${ }^{10} \mathrm{De}$ este modo, a Hegel se le coloca en medio de una discusión que su sistema no está interesado en responder en esos términos. Sin duda, Hegel estudió la "economía política" de su tiempo; en concreto, la de dos representantes de la ilustración escocesa: James Steuart ${ }^{11}$ (1707-1780) y Adam Smith (1723-1790). Según el testimonio de Karl Rosenkranz (1805-1879), Hegel realizó un comentario sistemático a

${ }^{8}$ Cfr. Charles Taylor, Hegel, 2010, México, Anthropos y Universidad Iberoamericana; Charles Taylor, Hegel y la sociedad moderna, 2014, México, FCE, trad. de Juan José Utrilla.

${ }^{9}$ Cfr. Carlos Ruiz Schneider, "El concepto hegeliano de eticidad y el comunitarismo", Seminarios de Filosofía, 12/13 (1999-2000), pp. 197-212. Para este autor, de los filósofos comunitarios, como Michael Walzer (1935-), Alasdair Macintyre (1929-), Michael Sandel (1953-), el pensamiento de Charles Taylor es el más cercano al de Hegel, especialmente por analizar las implicaciones del concepto de eticidad [Sittlichkeit], que remite a la obligación que cada individuo tiene hacia la comunidad existente de la que es parte. Véase Paulo Roberto Monteiro de Araujo, "Hegel and the libertarians" en Twentieth world congress of philosophy, Paideia, 1998, Boston, en <https://www.bu.edu/wcp/papers/poli/polimont.htm>, consultado el 13 de febrero de 2019.

${ }^{10}$ Sobre la relación de Hegel con la ciencia económica, uno de los textos fundamentales es N. Waszeck, The scottish enlightenment and Hegel's account of civil society, 1998, Dordrecht, Boston, Londres, Kluwer. Véase William Maker (comp.), Hegel on economics and freedom, 1987, Macon, GA., Mercer University Press; y Carsten Hermann-Pillath e Ivan Boldyrev (comps.), Hegel, institutions and economics. Performing the social, 2014, Nueva York, Routledge.

11 "Paul Chamley, profesor de economía de la Universidad de Estrasburgo, en su libro Economie politique et philosophie chez Steuart et Hegel, 1963, París, ha reconstruido los rastros de la influencia de Steuart en la concepción hegeliana de economía." Julio de Zan, La filosofía social y politica de Hegel. Trabajo y propiedad en la filosofía práctica, 2009, Buenos Aires, Ediciones del Signo, p. 65. 
RAFAEL GONZÁLEZ DÍAZ Y CARLOS J. MCCADDEN M.

la obra An inquiry into the principles of political economy $(1767)^{12} \mathrm{de}$ Steuart y su estudio fue decisivo en la concepción que Hegel tuvo en materia económica. De este modo lo expresa Rosenkranz:

Todo el pensamiento de Hegel sobre la esencia de la sociedad civil, la necesidad y sobre el trabajo, sobre la división del trabajo y la riqueza de las clases, la pobreza, la policía, los impuestos, etcétera, se concentran en un comentario continuo a la traducción alemana de la economía política de Stewart. ${ }^{13}$

Hegel menciona de manera explícita, en la observación del $\$ 189$ de su obra Principios de la filosofía del derecho, los trabajos de Adam Smith (1723-1790), David Ricardo (1772-1823) y Jean-Baptiste Say (1767-1832) como ejemplos del desarrollo de la economía política, que Hegel considera una de las ciencias que solo en la época moderna han podido encontrar su terreno propio. ${ }^{14}$ Como lo advierte Lisa Herzog, las agudas transformaciones económicas y sociales, en especial todo lo que se refiere a la consolidación de una sociedad de mercado por el intercambio económico, rompieron en buena medida muchas de las rígidas estructuras medievales en Inglaterra y Alemania. ${ }^{15}$ Estas novedosas trans-

84 formaciones fueron conocidas de manera directa por Smith y Hegel, porque tales cambios ocurrían precisamente en ese momento en sus países. De hecho, mientras que Smith escribe antes de la primera ola de industrialización en Gran Bretaña, Hegel recibe noticias sobre el desarrollo de Inglaterra a través de periódicos y revistas. Por eso, no es exagerado decir que los dos fueron los primeros en conceptualizar esta nueva realidad económica y tratar de comprender sus implicaciones. Por eso

${ }^{12}$ Este trabajo de James Steuart puede ser considerado, sin exageración, como el primer tratado sistemático y completo de economía política en la historia. Según Rosenkranz, Hegel comentó íntegramente la obra y su influjo fue decisivo en la concepción que tuvo en materia económica.

${ }^{13}$ Karl Rosenkranz, Vita di Hegel, 2012, Milán, Bompiani, trad. de Remo Bodei, p. 107. La traducción del italiano es nuestra.

${ }^{14}$ Cfr. Principios de la filosofía del derecho, 2005, Madrid, Edhasa, trad. de Juan Luis Vermal, p. 312.

${ }^{15}$ Cfr. Lisa Herzog, Inventing the market. Smith, Hegel, \& political theory, 2016, Oxford, Oxford University Press, pp. 6-7. 
también, la reflexión de ambos pensadores merece la atención de investigadores de distintas disciplinas. Yang Young-Sun estudia la relación entre la "economía" y la "teología" en ambos autores. Según YoungSun, el estudio de Smith y Hegel ilumina los "fundamentos teológicos" de las ideas económicas, tales como la salvación, la simpatía, el reconocimiento, la pobreza, el Estado, la mano invisible, la astucia, la escasez y la escatología. ${ }^{16}$

La influencia de Smith sobre Hegel y su diferencia con la de Steuart ha sido estudiada por Norbert Waszek (1983-). ${ }^{17}$ La idea central de Waszek, que se relabora en artículos de otros autores, es que Hegel es indiscutiblemente un autor liberal que incorpora en sus planteamientos algunos postulados de la economía escocesa pero que en su formulación no deja de ser novedoso. ${ }^{18}$ Hegel es liberal porque postula la libertad como fundamento de la vida social y política. Defiende que solo es congruente con la razón un régimen económico o político en el que se garantice el más amplio rango de "libertad negativa", entendida como carencia de una intervención estatal (laissez faire), para cada uno de sus integrantes. Un sistema económico, social y político en el que cada persona pueda expresar sus opiniones libremente, profesar la religión que quiera y poseer la máxima libertad de comercio y de trabajo sin la interferencia de un planificador central. ${ }^{19}$

${ }^{16}$ Cfr. Yang Young-Sun, Economies of salvation: Adam Smith and Hegel, 2012, Berna, Peter Lang.

${ }^{17} \mathrm{~N}$. Waszeck, op. cit.

${ }^{18}$ Cfr. Claudio Mario Aliscioni, El capital en Hegel. Estudio sobre la lógica económica de la filosofia del derecho, 2010, Buenos Aires, Homo Sapiens, pp. 43-49. La divergencia de perspectivas resulta proporcional al enfoque utilizado para comprender la concepción general de la vida práctica en Hegel. Cualquier intento que busque dar cuenta del significado de la "economía política" dentro del sistema hegeliano debe tomar en cuenta que esta se encuentra vinculada con la filosofía política y la filosofía de la historia del autor, en la esfera de lo que él llama "espíritu objetivo". Así, las formulaciones hegelianas tienen un origen más complejo y original de lo que podría parecer a simple vista. Véase Jürgen Lawrenz, "Hegel, recognition and rights: 'Anerkennung' as a gridline of the philosophy of rights; cosmos and history", The Journal of Natural and Social Philosophy, 3/2-3 (2007); Robert Pippin, Hegel's practical philosophy: rational agency as ethical life, 2008, Cambridge, Cambridge University Press; Robert Williams, Hegel's ethics of recognition, 2000, Berkeley, University of California Press; Richard Bellamy, "Hegel and liberalism", History of European Ideas, 8/6 (1987), pp. 693-708.

${ }^{19}$ Lisa Herzog, "Two ways of 'taming' the market. Why Hegel needs the police and the corporations", en Andrew Buchwalter (comp.), Hegel and capitalism, 2015, Suny Press, 
Hegel denomina "sistema de necesidades" a la compleja interdependencia de las preferencias y acciones de cada uno de los agentes que intervienen en la esfera económica y social. ${ }^{20}$ En un sistema racional hegeliano, las personas obran libremente de acuerdo con sus preferencias particulares y persiguen la satisfacción de sus intereses, y tales acciones e intercambios manifiestan un orden y una estructura determinada. La razón, y por ende la ciencia, tiene la tarea de desentrañar, a partir de esta masa aparentemente contingente de fenómenos, las regularidades y la necesidad (Notwendigkeit).

Así como la astronomía es la ciencia que encuentra las regularidades en el movimiento de los planetas que a simple vista parecen irregulares, la "economía política" tiene que exponer el "sistema de necesidades", esto es: "la relación y el movimiento de la masa de datos contingentes en su entrelazamiento o determinación cualitativa y cuantitativa". ${ }^{21}$ El interesante proceso que sigue el pensamiento para descubrir en medio de las necesidades y trabajos individuales, los principios simples de su intercambio; el pensamiento "descubre, a partir de la infinita cantidad de individualidades que en un primer momento tiene ante sí, los principios simples de la cosa, el entendimiento que actúa sobre ella y la gobierna". ${ }^{22}$

La economía política quiere encontrar lo necesario, las leyes por las que los hechos contingentes se agrupan e influyen entre sí. ${ }^{23}$ "Encontrar

pp.147-162. Véase también Lisa Herzog, Inventing the market. Smith, Hegel, and political theory, 2016, Oxford, Oxford University Press, pp. 119-146; Sybol Anderson, "Liberalism and recognition", en Dean Moyar (ed.), The Oxford handbook of Hegel, 2017, Oxford University Press, pp. 767-786; Sybol Anderson, Hegel's theory of recognition. From oppression to ethical liberal modernity, 2009, Londres, Bloomsbury, p. 185; Stephen Hudson, "The limitations of recognition. The complexity of actualizing freedom in Hegel's philosophy of right", en Arthur Kok y John van Houdt (comps.), Reconsidering the origins of recognition. New perspectives on german idealism, 2014, Cambridge, Cambridge Scholars Publishing, pp. 197; y Terry Pinkard, Does history make sense? Hegel on the historical shapes of justice, 2017, Londres, Harvard University Press, p. 47.

${ }^{20} \mathrm{Cfr}$. Hegel, Principios de la filosofia del derecho, p. 311.

${ }^{21}$ Loc. cit.

${ }^{22}$ Ibid., p. 312.

${ }^{23}$ Hegel, Principios de la filosofía del derecho, p. 312. 
aquí lo necesario es el objeto de la economía política, una ciencia que hace honor al pensamiento al hallar las leyes de una masa de hechos contingentes." 24 Los frutos del trabajo se relacionan recíprocamente, aunque en un primer momento todo parece abandonado al criterio de lo puramente singular. De la misma manera que el sistema planetario se manifiesta al observador como un conjunto de movimientos aparentemente caóticos e irregulares, los intercambios económicos están sujetos a la captación de las leyes que los explican. Dice Hegel:

Resulta un interesante espectáculo observar cómo todo nexo tiene su repercusión, cómo las esferas particulares se agrupan, influyen sobre otras, y son promovidas u obstaculizadas por ellas. Resulta sobre todo digno de señalarse este recíproco relacionarse en el que en un primer momento no se cree, porque todo parece abandonado al criterio arbitrario de lo singular. ${ }^{25}$

La "economía política" explica los principios simples que residen en las cosas que son producidas e intercambiadas, "el entendimiento que actúa sobre ellas y las gobierna". ${ }^{26}$ Descubrir la razón que actúa en las cosas económicas produce la conciliación y el entendimiento económico. Pero esta misma racionalidad económica es el objeto "en el que el entendimiento de los fines subjetivos y las opiniones morales descarga su descontento y fastidio moral". ${ }^{27}$ La comprensión de las leyes económicas produce una gran satisfacción intelectual, ya que se descubre el porqué de los fenómenos, si bien no necesariamente se deben compartir moralmente las consecuencias.

${ }^{24}$ Loc. cit.

${ }^{25} \mathrm{Id}$.

${ }^{26} \mathrm{Id}$.

${ }^{27} I d$. Dice Vieweg: "La ciencia económica se ha convertido en una disciplina que preside la mayor parte de las decisiones en el ámbito público. La naturaleza de sus postulados y el uso creciente de las matemáticas la convierten en la herramienta por antonomasia no solo para explicar los intercambios de bienes sino para diseñar cualquier política pública”. Klaus Vieweg, La idea de libertad. Contribuciones a la filosofía práctica de Hegel, 2009, México, UAM-Centro de estudios filosóficos José Porfirio Miranda, p. 13. 


\section{Sobre la naturaleza de las necesidades humanas}

La satisfacción de las necesidades humanas básicas y fundamentales, como la de alimentarse, vestirse, etc., según Hegel, dependen de condiciones exteriores contingentes, pero todas las variaciones arbitrarias producen determinaciones universales. ${ }^{28}$ Detrás de la aparente dispersión de las circunstancias que afectan la satisfacción de las necesidades, todas surgen de la naturaleza de las cosas mismas: "la falta de pensamiento es contenida por una necesidad que surge por sí sola”. ${ }^{29}$ Para Hegel, lo propio de las necesidades humanas está en su carácter universal, que supera a las de los animales y que las vuelve ilimitadas. ${ }^{30}$ En el caso de los seres humanos, las necesidades y los modos de satisfacción se multiplican y luego se descomponen y diferencian progresivamente en necesidades particularizadas y por lo mismo más abstractas. El ser humano tiene deseos infinitos; ${ }^{31}$ al desear espiritualmente, su avidez no tiene límite. Dice Hegel:

El hombre muestra al mismo tiempo que va más allá del animal y revela su universalidad, en primer lugar por la multiplicación de las necesidades y los medios para su satisfacción, y luego por la descomposición y diferenciación de las necesidades concretas en partes y aspectos singulares que se transforman de esta manera en distintas necesidades particularizadas y por lo tanto más abstractas. ${ }^{32}$

La multiplicación de las necesidades humanas descansa en la condición espiritual del hombre y en las exigencias que nacen de la cultura

${ }^{28}$ Cfr. Carla Cordua, "Hegel sobre las necesidades humanas", Revista de Filosofia, 57 (2001), pp. 174-179.

${ }^{29}$ Hegel, Principios de la filosofia del derecho, p. 312.

${ }^{30} \mathrm{Hegel}$ describe de este modo la infinidad de las necesidades que se crean en la sociedad: "La tendencia de la situación social a multiplicar y especificar indeterminadamente las necesidades, los medios y los goces, que no tienen límites, lo mismo que la diferencia entre necesidades naturales y cultivadas". Ibid., p. 316.

${ }^{31}$ Para Aristóteles los deseos son ilimitados, mientras que las necesidades son limitadas. Esto distingue la verdadera riqueza de la pura acumulación crematística. Véase Carlos McCadden, La clase media en la res publica mexicana, en $<\mathrm{http}$ ://www.usemcdmx.org.mx/resources/ documents/clase media res publica.pdf> p. 6 y ss., consultada el 18 de febrero de 2019.

${ }^{32} \mathrm{Cfr}$. Hegel, Principios de la filosofia del derecho, p. 312. 
que dicta los criterios del gusto y de la utilidad que tienen los diferentes objetos que se ofrecen para el consumo individual. Así, "no es ya la necesidad misma sino la opinión la que tiene que ser satisfecha, y pertenece precisamente a la cultura descomponer lo concreto en sus particularidades". ${ }^{33}$ La multiplicación de las necesidades humanas hace que también se dividan y multipliquen los medios para satisfacerlas, sobre todo cuando se han particularizado hasta el extremo. A medida que las necesidades se multiplican al infinito, los trabajos se tienen que especializar para que los medios sean adecuados a los fines; ${ }^{34}$ de ahí surge la división del trabajo que es una pieza fundamental en pensamiento económico de Adam Smith. ${ }^{35}$

Además, como las necesidades y los medios para satisfacerlas son para Hegel un ser-para-otro, las necesidades y los trabajos se condicionan recíprocamente entre las personas. Es decir, la necesidad, el trabajo y su satisfacción son intrínsecamente sociales: "Las necesidades y los medios son, en cuanto existencia real, un ser para otro, cuyas necesidades y cuyo trabajo [Arbeit] condicionan recíprocamente su satisfacción" ${ }^{36}$ Sin embargo, no solo la satisfacción de las necesidades y los trabajos son interdependientes, sino que la actividad que cada individuo realiza depende del lugar o el estatus que tiene en la sociedad. Para Hegel, las necesidades y los trabajos económicos de los individuos son tan específicos que determinan las relaciones sociales que tienen entre sí. "La abstracción, que es una cualidad de las necesidades y de los medios, deviene también una determinación de las relaciones de los individuos entre sí". ${ }^{37}$ El mercado es la universalidad en el que las personas pueden reconocerse y en el que las necesidades y el trabajo singulares son al mismo tiempo algo real y significativo para la sociedad. Dice Hegel:

${ }^{33} \mathrm{Ibid}$., p. 314. Por eso, para Hegel la creación de necesidades se fundamenta en la ganancia que obtienen algunos individuos con ellas. Así lo expresa en este parágrafo: "Por eso, la necesidad no es producida tanto por los que la poseen de un modo inmediato sino por quienes buscan una ganancia con ella".

${ }^{34}$ Ibid., p. 314.

${ }^{35}$ Cfr. Smith, Investigación sobre la naturaleza y causas de la riqueza de las naciones, 1981, México, FCE, pp. 7-9.

${ }^{36}$ Principios de la filosofia del derecho, p. 314.

${ }^{37}$ Loc. cit. 
"Esta universalidad, en el sentido de reconocimiento [Anerkanntsein], es el momento que convierte a las necesidades, los medios y modos de satisfacción en su singularidad y abstracción, en algo concreto, en cuanto social', 38

\section{EI dinero y las relaciones sociales}

Para Hegel, la riqueza [Reichtum] es el resultado de la suma total de los esfuerzos y las obras de la que es capaz una cultura, la esencia espiritual universal. Es aquello que se produce por el trabajo de todos y se consume así mismo en el disfrute de todos y de manera continua:

La riqueza [es] la esencia espiritual universal, así como el resultado que deviene constantemente del trabajo [Arbeit] y de la actividad de todos, igual que vuelve luego a disolverse en el disfrute [Genuß] de todos. ${ }^{39}$

El individuo tarde o temprano se hace consciente de que la sustancia ética en la que desenvuelve su vida es la cultura y que no puede apoderarse de la misma sin el trabajo por medio del cual le da forma al mundo. La riqueza, por lo tanto, es la del individuo y la de todos porque aglutina los esfuerzos y los logros de una sociedad. Surge del conjunto de experiencias preexistentes y del patrimonio acumulado por una comunidad. La conciencia individual está cierta de que ese mundo es su sustancia cultural. El ser humano en el mundo en cuanto "autoconciencia pasa a apoderarse de él; [y] alcanza este poder sobre el mundo por medio de la cultura". ${ }^{40}$ Las acciones que emprende el individuo son una obra universal que tiene fundamento en la universalidad. Su vida y su quehacer son el fruto de la riqueza cultural acumulada y su actividad se convertirá en patrimonio general: "Esta sustancia etérea simple de su vida, por esta

${ }^{38}$ Ibid., pp. 314-315.

${ }^{39}$ Fenomenología del espíritu, 2010, Madrid, Abada Editores, p. 587.

${ }^{40} \mathrm{Ibid}$., p. 583. Para Hegel, el individuo supera la existencia inmediata y se desarrolla como particularidad autoconsciente: "su formación cultural y su propia realidad efectiva son, por tanto, la realización efectiva de la substancia misma". 
determinación de su inmutable igualdad a sí misma, es ser, y por ende, únicamente ser para otro". ${ }^{41}$

La verdad del concepto de riqueza está en el movimiento dialéctico. Por un lado, la riqueza del individuo es la que adquiere de la sociedad a través de la cultura, es la de todos como el conjunto de conocimientos y técnicas que le permiten obrar en el mundo; y por el otro, la riqueza producida por un individuo se convierte en el patrimonio material y espiritual general de todos. ${ }^{42}$ La riqueza de cada uno es en cierto sentido la de todos y viceversa. La riqueza particular no deja de ser-para-otro, y si quiere ser verdaderamente comprendida, no puede serlo sino a partir de lo que Hegel llama la lógica de la contradicción. ${ }^{43}$

Pero, ¿qué es el dinero para Hegel? De manera explícita dice que es el medio de cambio universal en el que se hace efectivo el valor abstracto de todas las mercancías. El "medio de cambio [Tauschmittel] universal, [es] el dinero [Geld], en el cual es efectivo el valor [Wert] abstracto de todas la mercancías [Waren] ". ${ }^{44}$ Además, el dinero es un signo en torno del cual se reúnen los hombres para hacer presente todas las cosas y la necesidad misma pero no de manera directa, sino que solo se expresan cuantitativamente las cualidades de los objetos. "El dinero [Geld] representa todas las cosas, pero en la medida en que no expone la necesidad misma, sino que es solo un signo [Zeichen] de ellas, es a su vez gobernado por el valor específico, al que solo expresa como algo abstracto". ${ }^{45}$ Los objetos pueden ser diferentes en su existencia específica, pero el valor es todo aquello que hay de internamente igual en ellos y que por eso mismo puede ser elevado a lo universal. "Si se considera el concepto

${ }^{41}$ Ibid., p. 583.

${ }^{42}$ Ibid., p. 587. "Es, pues, en sí, inmediatamente, lo opuesto de sí misma, riqueza [Reichtum]. Aunque la riqueza, ciertamente, es lo pasivo o lo nulo."

${ }^{43}$ Carlos McCadden y José Manuel Orozco. "Hegel no-Hegel, ¿Contradice la contradicción de Hegel?", Estudios, 104 (2013), pp. 47-79. También en <http://estudios.itam.mx/sites/default/ files/estudiositammx/files/104/000196508.pdf $>$, consultada el 16 de enero de 2019.

${ }^{44}$ G. W. Friedrich Hegel, Lineas fundamentales de la filosofía del derecho, 2010, Madrid, Gredos, trad. María del Carmen Paredes, p. 195. Para Hegel, el estamento del comercio [Handelsstand] es el que tiene la tarea del intercambio de los medios singularizados que permiten la satisfacción de las necesidades.

${ }^{45}$ Hegel, Principios de la filosofia del derecho o derecho natural y ciencia política, p. 149. 
de valor [Wert], se verá la cosa misma solo como un signo [Zeichen] y no regirá por sí misma, sino por lo que vale $[$ Wert $]$ ". ${ }^{46}$ El valor puede ser diverso según las necesidades, pero lo abstracto es precisamente lo que caracteriza al dinero. El valor de un objeto puede ser más o menos apto para esta necesidad específica, pero si se piensa el objeto más allá de sus cualidades, en cuanto abstracción del valor, entonces es pensado meramente como cantidad, es decir, como dinero: "Una letra de cambio, por ejemplo, no representa su naturaleza de papel, sino que es un signo [Zeichen] de otro universal, del valor". ${ }^{47}$ Por ello, para Hegel "el valor de una cosa puede ser muy diverso en relación con las necesidades, pero si se quiere expresar no lo específico sino lo abstracto del valor [Wert] se tendrá entonces el dinero [Geld] ". ${ }^{48}$

El hombre imprime con su trabajo determinadas cualidades a los objetos para que estén en condición de satisfacer las diversas necesidades. El valor del objeto depende de estas cualidades, y del grado en el que las mismas corresponden a las necesidades que quieren satisfacer, por eso cada objeto es comparable y puede ser medido. La cualidad para Hegel solo se determina cuantitativamente. Y la cantidad se funda en la cualidad. El entendimiento no solo considera el aspecto cualitativo del objeto, sino el cuantitativo y por eso mismo, la cosa es más o menos valiosa porque satisface en determinada magnitud una necesidad. "Lo cualitativo desaparece aquí en la forma de lo cuantitativo. La necesidad es el título bajo el que se presentan las cosas más variadas, y lo que les otorga esa comunidad por la que pueden ser medidas". ${ }^{49}$

A la hora de considerar las necesidades humanas, el entendimiento transita de lo cualitativo a lo cuantitativo como se hace en las matemáticas. ${ }^{50}$ El valor es, por lo tanto, la determinación cuantitativa que surge

${ }^{46}$ Loc. cit.

${ }^{47} \mathrm{Id}$.

${ }^{48} \mathrm{Id}$.

${ }^{49} I d$.

${ }^{50} I d$. Hegel relaciona el dinero y el valor con las matemáticas; por ejemplo, si se quiere definir una figura en relación con otra completamente diferente, se puede ver de inmediato que son específicamente distintas pero sus diferencias solo se determinan para el entendimiento cuantitativamente. Así lo expresa Hegel: "algo similar sucede en las matemáticas. Si defino el círculo, la elipse y la parábola, se verá que son específicamente distintos. A pesar de ello, la diferencia de estas distintas curvas se determina en forma meramente cuantitativa; solo depende de una diferencia 
de una determinación cualitativa. La cualidad otorga la unidad de medida o magnitud para que la cosa sea objeto de intercambio y abstracción. "El valor [es] lo que hay de internamente igual en las cosas, que son completamente diferentes en su existencia específica [...] y gracias al cual la representación de la característica inmediata de la cosa se eleva a lo universal". ${ }^{51}$ Por ello el valor de uso es lo cualitativo y el valor de cambio lo cuantitativo y lo universal.

Este valor universal (dinero) puede ser referido a todas las cosas y prestaciones $;{ }^{52}$ por ejemplo, la propiedad puede dejar de considerarse un valor específico y mirarse solo como valor abstracto o en dinero. Dice Hegel: "En la propiedad [Eigentum] la determinación cuantitativa que surge de la cualitativa es el valor [Wert]. Lo cualitativo da aquí el cuánto para la cantidad, y como tal se conserva al mismo tiempo que es eliminado". ${ }^{53}$ La casa es un lugar para vivir y sin dejar de ser casa ahora es una cantidad de dinero. La propiedad tiene esta doble dimensión, la del uso y la del valor.

Sin embargo, a lo largo de la historia se han intentado implantar ordenamientos jurídicos que van en contra del concepto de propiedad. Incluso se ha sostenido que un individuo puede ser propietario de una cosa sin ser, al mismo tiempo, el dueño de su valor. Se pretende que "se puede ser propietario [Eigentümer] de una cosa sin serlo al mismo tiempo de su valor". 54

cuantitativa referida al coeficiente, es decir, a la magnitud meramente empírica." Todo el mundo es magnitud, la cualidad es cantidad, lo cual repugna al pensamiento clásico.

${ }^{51}$ Hegel, Lineas fundamentales de la filosofia del derecho, pp. 111-112. Aquí, el desarrollo del pensamiento transita de la cualidad específica de una cosa a la cantidad como indiferencia de esta anterior determinación. Cfr. Principios de la filosofía del derecho o derecho natural y ciencia politica, p. 149.

${ }^{52}$ Loc. cit.

${ }^{53} \mathrm{Id}$. Entonces la propiedad tiene esta doble dimensión el uso y el valor. De tal modo que un alguien podría ser dueño de todo el dinero del mundo sin ser dueño de una cosa específica y viceversa, que alguien sea el dueño de todas las cosas y no posea dinero, porque lo propio del dinero es que pueda equipararse una cosa por otra. La propiedad es el título, que se asigna al puro valor abstracto o a un valor específico según el caso particular. Puede haber casos en los que una persona puede ser propietaria de un bien sin serlo del valor, pero para Hegel la realidad más adecuada al concepto de propiedad no acepta este tipo de limitaciones.

${ }^{54} \mathrm{Id}$. Una familia que no puede vender [verkaufen] o hipotecar sus bienes no es dueña del valor. 
Para Hegel, este tipo de disposiciones legales que intentan separar la propiedad de su valor no corresponden verdaderamente al concepto de propiedad y esto explica que hayan ido cayendo en desuso. "Dado, sin embargo, que esta forma de propiedad [Eigentum] no es adecuada al concepto de propiedad, estas limitaciones (feudo, fideicomiso, [ejido]) en su mayoría están desapareciendo". ${ }^{55}$

El dinero mismo puede ser objeto del contrato, por ejemplo, de donación, o préstamo, porque se le considera una cosa universal con valor: "[1] a cosa [objeto de la donación] es en este caso o una cosa específica, o si no, aunque sea tal, que sea considerada como una cosa universal o que valga [gilt] (como el dinero [Geld]) como cosa de por sí universal". ${ }^{56}$ En los contratos que Hegel denomina de cambio [trueque], una cosa específica puede ser cambiada por otra similar, o en la compraventa [Kauf-Verkauf] la cosa es cambiada por "una que está determinada como cosa universal, es decir, que cuenta solo como valor [Wert] sin otra determinación específica para su utilización [Benutzung]: es decir, por dinero [Geld] ". ${ }^{57}$

La naturaleza del préstamo es la misma: una persona es propietaria de la cosa universal, del valor y de los intereses. El valor abstracto es objeto de reconocimiento jurídico como cosa de la que alguien es propietaria y, por ende, de los beneficios que puede producir. Así deben ser entendidos los contratos de cambio de una cosa universal, de modo que "el prestatario [Verleiher] solo sigue siendo propietario [Eigentümer] de esta [del dinero] o, lo que es lo mismo, del valor [Werte]: es el préstamo [Anleihe] (mutuum, también commodatum con un interés [Mietzins])". ${ }^{58}$ El prestatario es, pues, dueño del dinero y de su valor, el dinero se vuelve cosa.

\section{¿El dinero hizo al mundo más justo?}

No solo la "propiedad" puede ser contemplada como un "valor abstracto", esto es, como dinero, sino que lo mismo ocurre con cualquiera otra

${ }^{55} I d$.

${ }^{56}$ Lineas fundamentales de la filosofia del derecho, p. 96.

${ }^{57}$ Loc. cit.

${ }^{58} \mathrm{Id}$. 
"prestación" que los hombres intercambian. Un "trabajo", al contemplarse abstractamente, puede ser representado en "dinero" y servir de medio en la relación entre los hombres. ¿Qué significó el dinero en la historia de las relaciones entre las personas? Para Hegel, el dinero permitió que los individuos se relacionaran entre sí de manera más equitativa y que el valor del trabajo pudiera determinarse de manera más justa. Imaginémonos por un momento que desaparece el dinero como medio de cambio y que los trabajos no tienen algo que permita su intercambio, ¿cómo se adquiriría una propiedad? ¿Cómo se podría pagar por un trabajo? Si no hay trabajo ni propiedad, ¿cómo estaría organizada la sociedad? ¿Podría construirse la justicia sin mercado?

En la Antigüedad, la relación entre las personas se fundaba en la "superioridad innata" de una clase sobre otra y no se consideraba como algo determinante el respeto al principio de la libertad. A los individuos se les distribuía en clases y a los que por "naturaleza" correspondía servir se les exigía de manera indeterminada e ilimitada la prestación de servicios particulares, lo que intrínsecamente negaba su autonomía. En su formulación clásica, el esclavo es un "instrumento para la acción del hombre libre", una cosa que no es completamente un hombre. ${ }^{59}$ A esta clase de "hombres" no les corresponde ser libres sino servir. Por eso el siervo no es dueño de su trabajo, porque no se posee a sí mismo y si no es dueño de su trabajo no puede cambiarlo por dinero. Solamente si los esclavos o los siervos fueran dueños de sí mismos y de su trabajo podrían estar en condiciones de ponerle precio a sus acciones y ser reconocidos en el ámbito social, económico y político. El dinero tiene mayor relevancia en una sociedad en el que se estima la libertad del individuo.

Para Hegel, el reconocimiento [Anerkennung] no solo tiene una significación política, sino también económica. La expresión paradigmática de los tipos de reconocimiento fue analizada por Hegel en el famoso pasaje de la Fenomenología que versa sobre dominación y servidumbre en el capítulo IV, en el que reflexiona sobre la autoconciencia, el mismo

${ }^{59}$ Alfredo Gómez-Muller, Alteridad y ética desde el descubrimiento de América, 1997, Madrid, Akal, pp. 26-32. 
RAFAEL GONZÁLEZ DÍAZ Y CARLOS J. MCCADDEN M.

fragmento que Alexandre Kojève (1902-1968) popularizó como “la dialéctica del amo y el esclavo". ${ }^{60}$

Durante la esclavitud y las monarquías feudales el siervo prestaba servicios subordinados e indeterminados a su señor. El siervo no era libre y tampoco lo era su trabajo. En esas circunstancias, carecía de sentido determinar el valor de su trabajo. Sin libertad, las acciones no tienen valor objetivo, la particularidad que es la fuente de la determinación desaparece. Sin libertad no hay precio ni mercado. Para Hegel, el intercambio de servicios y de los productos por medio del dinero se funda precisamente en lo contrario, en el respeto al principio de la libertad subjetiva. Si alguien vende un servicio, prestación o producto es porque le pertenece, es el propietario de la cosa o de la acción y si esta fue realizada es por su voluntad particular. El dinero hizo al mundo más justo y equitativo porque permitió que el intercambio entre los hombres estuviera fundado en la libre voluntad y el árbitro de las partes.

El proceso de liberación de lo individual fue el que consolidó al dinero como medio de cambio universal y posibilitó al mismo tiempo el mutuo reconocimiento de los hombres. Por eso, a medida que el dinero fue convirtiéndose en un aspecto central del nuevo modo de relación entre los individuos, la libertad individual se fue consolidando. El desarrollo del dinero acompaña el de la libertad. Negar el intercambio económico por medio del dinero es negar la libertad individual. La "realidad efectiva" del principio de la libertad subjetiva supone que el quehacer del individuo, sin dejar de ser particular y estar mediado por su voluntad, alcance la forma del valor universal. Para Hegel, esa condición solo es posible con el dinero:

En estas relaciones falta el principio de la libertad subjetiva, a saber, que el hacer sustancial del individuo, que en tales prestaciones es de todos modos algo particular por su contenido, esté mediado por su voluntad

${ }^{60} \mathrm{Hegel}$ no usa la expresión dialéctica del amo y del esclavo, sino que este pasaje corresponde a una sección del capítulo IV de la Fenomenología, titulada autonomía y no autonomía de la conciencia; dominación y servidumbre. Alexandre Kojève (1902-1968) la denominó dialectique du maître et de l'esclave, Alexandre Kojève, Introducción a la lectura de Hegel, 2013, Madrid, Trotta, trad. de Andrés Alonso Martos, pp. 95-98. 
particular, un derecho que únicamente es posible por la exigencia de las prestaciones en la forma del valor universal [dinero] y que es el fundamento que ha dado lugar a esta transformación. ${ }^{61}$

A pesar del rechazo que puede generar la idea de que el dinero permite relaciones más equitativas entre las personas, el dinero es un objeto de confianza que los miembros de una sociedad aceptan como forma de la riqueza almacenada y como medio que facilita la transacción entre las personas. Inclusive, reconociendo la necesidad de medios más eficaces y más justos para intercambiar el trabajo y las mercancías es mejor contar con el dinero como medio de cambio que carecer de él.

Además, los intercambios entre los individuos fueron más equitativos cuando a la prestación de un servicio le siguió su pago en dinero. A partir de este momento, se respetó la voluntad particular y esta fue el fundamento de un contrato en el que las personas se reconocen mutuamente. Por medio de este acuerdo de voluntades el trabajo pudo empezar a determinarse. Una de las personas tiene la capacidad de cambiar este trabajo concreto por este monto; la otra, de otorgarlo o no. Solo con el dinero los trabajos pudieron determinarse de manera más justa. La prestación de un servicio o un trabajo ya no quedaba indeterminada y sin valor. La voluntad particular, por la que se compra y se vende, se media a sí misma en el valor universal o dinero. En las sociedades modernas, las personas intercambian trabajos y bienes por medio de dinero que es de por sí el "valor universal existente de las cosas" y en él, los servicios quedan circunscritos a lo previamente pactado por las partes. Así lo expresa Hegel:

Lo que se ha de realizar en prestación, en tanto que se puede reducir a dinero [Geld] como valor efectivamente universal de las cosas y de las prestaciones, puede ser determinado de un modo justo y a la vez de manera que los trabajos [Arbeiten] y servicios particulares que se pueden prestar al individuo estén mediados por su arbitrio. ${ }^{62}$

${ }^{61}$ Lineas fundamentales de la filosofía del derecho, p. 195.

${ }^{62}$ Ibid., p. 274. Las cursivas son nuestras. 
El dinero como medio de cambio en el que se hace efectivo el valor abstracto de los objetos permite que las cosas, los servicios e incluso los delitos puedan ser reparados parcialmente por dinero. En épocas pretéritas, por ejemplo para los servicios al Estado, se tomaban en mayor medida las condiciones concretas del individuo y "se le convocaba según su habilidad [Geschicklichkeit] para el trabajo [Arbeit]". ${ }^{63}$ En el mundo moderno, las prestaciones se reducen al dinero. "Por lo que respecta a las prestaciones [Leistungen], en la actualidad se reducen casi todas a dinero [Geld] " ${ }^{64}$ No solo un individuo particular compra a otro lo que necesita, sino que el Estado mismo se satisface con prestaciones abstractas y crea obligaciones dinerarias.

El Estado moderno no demanda de sus ciudadanos ninguna prestación directa y los exenta de un servicio particular, de las muchas habilidades, actividades y talentos, de "los infinitamente variados patrimonios vivos que se encuentran en ellos, y que al propio tiempo están ligados a la disposición del ánimo, el Estado [...] solo pretende el único patrimonio que aparece como dinero ". ${ }^{65}$ El Estado prefiere garantizar su protección en la forma de un valor universal, porque el dinero no es un patrimonio particular, sino que es lo universal: "Pero, de hecho, el dinero no es un patrimonio particular al lado de los demás, sino que es lo universal de ellos en la medida en que se producen en la exterioridad de la existencia concreta, en la cual puede ser aprendidos como una cosa". ${ }^{66}$ El dinero tiene la ventaja de volver concreto lo abstracto, porque solo en cuanto exterior podría recibir la determinación cuantitativa y el medio idóneo para la justicia y la igualdad de los servicios previamente acordados.

Así, el dinero como medio de cambio de servicios y trabajos permitió que la relación fuera más equitativa entre las personas, que ya no se relacionan por una subordinación natural ni por un acuerdo indeterminado del tipo de trabajo o servicio que se ven obligadas a realizar,

\footnotetext{
${ }^{63}$ Principios de la filosofía del derecho o derecho natural y ciencia política, p. 449.

${ }^{64}$ Loc. cit.

${ }^{65}$ Lineas fundamentales de la filosofia del derecho, p. 195.

${ }^{66}$ Loc. cit.
} 
sino que se funda en el respeto de la autonomía individual y según los méritos de cada quien:

Por medio del dinero [Geld] la justicia de la igualdad puede llevarse a cabo mucho mejor, pues de otro modo, si se tratara de la capacidad concreta, el hombre talentoso sería gravado más que el hombre sin talento. Ahora se muestra en cambio respeto por la libertad subjetiva al tomar de las personas solo aquello que se les puede tomar [ergriffen].${ }^{67}$

Para Hegel, el dinero es un medio de cambio universal que permitió históricamente una nueva forma de relación entre los hombres y que se impuso como un sistema general de intercambio hasta que se pudo reconocer y respetar el principio de la autonomía individual. En el acto de cambiar cosas y servicios por dinero está implícito el reconocimiento de la igualdad con el individuo con el que se realiza el intercambio, el respeto de la voluntad libre de los que acuerdan el cambio y finalmente que la persona que entrega un servicio recibe lo que le corresponde.

\section{El dinero y la "inconmensurabilidad" del trabajo}

El dinero como medio de cambio tiene límites que Hegel no desconoce, por ejemplo, en lo que se refiere a la retribución de un delito por medio de dinero. Hegel se da cuenta que el dinero, como la igualdad abstracta de las cosas, al caer en la esfera de la exterioridad y, por lo tanto, en el campo de la finitud, dificulta la determinación absoluta del valor que, sin embargo, debe acotarse de algún modo y, por ende, solo permite una aproximación permanente. ${ }^{68}$ Cuando la determinación fundamental de

${ }^{67}$ Principios de la filosofía del derecho o derecho natural y ciencia politica, p. 449. Las cursivas son nuestras.

${ }^{68}$ Cfr. Líneas fundamentales de la filosofía del derecho, pp. 111-112. Hegel lo expresa de este modo: "La caracterización cualitativa y cuantitativa del delito y su superación [Aufheben]

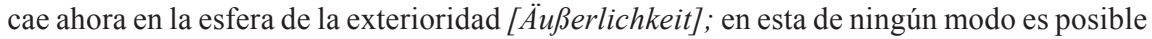
una determinación absoluta (compárese $\$ 49$ ); esto sigue siendo en el campo de la finitud solo una exigencia que el entendimiento siempre tiene que limitar cada vez más, lo cual es de suma importancia, pero que progresa al infinito y solo permite una aproximación que es perenne". 
una cosa es lo infinito, desaparece la especificidad externa y lo único que queda es la igualdad fundamental para lo esencial. El dinero como forma universal puede ser regla de igualdad esencial, pero no en la especificidad externa. ${ }^{69}$ "Solo según este último aspecto el hurto, el robo, la multa [Geld] y la pena de cárcel, etc., son claramente desiguales, pero según su valor de ser en su propiedad universal trasgresiones son equiparables $"{ }^{70}$ El dinero como medio de cambio en el que se hace efectivo el valor abstracto de los objetos permite que las cosas, los servicios e incluso los delitos puedan ser reparados parcialmente. La retribución dineraria quiere superar el delito en toda su extensión cuantitativa y cualitativa. "Esta identidad que descansa en el concepto no es sin embargo la igualdad en la característica específica de la trasgresión, sino en la característica que es en sí (an sich), según el valor [Wert] de la misma". ${ }^{71}$

El dinero hace equiparable los objetos y los trabajos pero no puede esperarse que logre la perfecta igualdad de lo que se intercambia. Por ejemplo, la cantidad de dinero que se otorga a cambio de un delito no puede reparar absolutamente la transgresión a la ley ni acercarse al daño específico y real que ha causado, pero si se capta el significado del valor en cuanto tal se descubren los límites y posibilidades de la equiparabilidad en la esfera del valor. Lo mismo cuando se establece un "contrato de salario" [Lohnvertrag] para retribuir un trabajo o servicio por una obra determinada que se puede enajenar por cierto tiempo. ${ }^{72}$

Según Hegel, en algunos casos la "prestación" o el "trabajo" tiene una cualidad tal que la vuelve "inconmensurable" en términos de dinero $\mathrm{y}$, por lo tanto, ese servicio no tiene equivalencia en la forma de salario, hay algo que el dinero no puede pagar en todo tipo de trabajo:

Afines a este son el mandato y otros contratos, en los que la prestación [Leistung] se basa en el carácter y la confianza o en talentos más altos,

${ }^{69}$ Loc. cit.

${ }^{70} I d$.

${ }^{71} I d$.

${ }_{72}$ Ibid., p. 96. En esto consiste para Hegel: "el contrato de salario [Lohnvertrag] (locatio operae), [o] enajenación de mi producir o de prestar servicios, en la medida en que son enajenables, por un tiempo limitado o con alguna otra limitación (vid. § 67)”. 
y donde surge una inconmensurabilidad [Inkommensurabilität] de lo ejecutado frente a un valor externo (que aquí no se llama salario [que se trata de hacer equivalente como], honorario [Honorar]). ${ }^{73}$

Un salario no es un honorario; todo trabajo supone algún tipo de salario por lo que se cuantifica la actividad y un honorario por aquello que es verdaderamente inconmensurable. El dinero solo tiene sentido como superación de las especificidades que renuncia a la posibilidad de lograr absolutamente la igualdad, pero que reconoce como posible la equiparación de las diferencias que se conservan y de las que no desaparecen las contradicciones y las insuficiencias. Es algo semejante a lo que dijo Hegel cuando afirmó:

Así que, como se dijo antes, es cosa del entendimiento buscar la aproximación en la igualdad de sus respectivos valores. Si no se capta la conexión existente en sí entre el delito y su aniquilación y por tanto el pensamiento del valor y de la equiparabilidad de ambos, según el valor [Wert $].{ }^{74}$

\section{El Estado y el mercado}

Para Hegel, el Estado carecería de sentido sin el mercado, que es el ámbito en el que se desarrolla el sistema de necesidades, el espacio-tiempo en el que los miembros de una sociedad se reúnen para intercambiar su trabajo y los productos que genera. El mutuo reconocimiento no solo se alcanza en la esfera política, sino también en la económica. En virtud del mercado, los hombres establecen relaciones comerciales en las que intercambian bienes y servicios para satisfacer sus necesidades; es un acto cargado de significado social. ${ }^{75}$ Una institución u organización social que permite a las personas reconocerse y alcanzar el desarrollo pleno de su personalidad. El pluralismo acompaña la noción de mercado; sin embargo, para Hegel la particularidad nunca está desligada de lo que él denomina la universalidad. ${ }^{76} \mathrm{El}$ mercado es un acto

${ }^{73}$ Loc. cit.

${ }^{74}$ Ibid., pp. 111-112.

${ }^{75}$ Ibid., pp. 314-315.

${ }^{76}$ Lineas fundamentales de la filosofía del derecho, p. 315. 
social aunque sea realizado por hombres a título personal. El Estado, por lo tanto, no disuelve las diferencias personales ni las particularidades, no es concebible sin el mercado como sistema en el que cada individuo tiene la capacidad de obrar y perseguir libremente sus objetivos. ${ }^{77}$ Lo que llamamos mercado es la totalidad de las relaciones de los individuos en la esfera del intercambio, de modo que si tratamos de concebir el mercado solamente como la pura agencia racional de los individuos atomizados no habría mercado. No habría interdependencia ni relación. ${ }^{78} \mathrm{El}$ mercado supone las relaciones sociales y la posibilidad de intercambiar libremente. Por eso, el individuo tiene que entrar al mercado, mejor aún, está en el mercado y si está en el mercado está en un conjunto de relaciones. Si el individuo está en el mercado está en una relación social y política, si no estuviera en el mercado no estaría en la sociedad. ${ }^{79}$

Sin embargo, para Hegel, de la misma manera que no es posible concebir al Estado sin mercado, este último requiere para su correcto funcionamiento un conjunto de disposiciones sociales, jurídico-políticas y culturales que solo pueden garantizarse plenamente en el Estado. ${ }^{80}$ Hegel utiliza expresiones que fuera de su sistema podrían ser interpretadas en un sentido totalitario; por ejemplo, la definición de Estado que encontramos en el $\S 258$ :

El Estado, en cuanto realidad de la voluntad substancial, realidad que esta tiene en la autoconciencia particular elevada a su universalidad, es lo racional en y para sí. Esta unidad substancial es el absoluto e inmóvil fin de sí mismo en el que la libertad alcanza su derecho supremo, por lo que este fin último tiene un derecho superior al individuo, cuyo supremo deber es ser miembro del Estado. ${ }^{81}$

El Estado es la voluntad elevada a su universalidad. Lo que según el concepto es racional en y para sí. El lugar en el que la libertad alcanza su derecho supremo, es decir, deja de ser una pura noción abstracta

${ }^{77}$ Principios de filosofía del derecho, p. 320.

${ }^{78}$ Ibid., p. 319.

${ }^{79}$ Ibid., p. 320.

${ }^{80}$ Ibid., p. 339.

${ }^{81}$ Ibid., p. 370. 
para ser realidad efectiva. ${ }^{82}$ El Estado es racional porque es la riqueza social más grande, el conjunto de las relaciones que se objetivan. Y si bien los individuos persiguen sus propios intereses, esos fines, aparentemente egoístas, resultan benéficos para la sociedad. La afamada expresión "Nichts in der Welt geschieht ohne grosse Leidenschaft", 83 que se traduce habitualmente como "Nada acontece en el mundo sin una gran pasión”, expresa la compleja articulación entre los deseos individuales y el carácter social de los mismos. La absoluta compenetración de la particularidad con lo universal. Por eso, cada una de las grandes figuras de la historia no solo realiza un querer particular, sino que le revelan a cada época su propia necesidad. En las Lecciones de la filosofía de la historia universal (1837), Hegel sostiene que es difícil saber lo que se quiere; frecuentemente se puede querer algo y estar precisamente en el punto negativo. En este sentido, algunos hombres particulares representan precisamente este querer afirmativo. ${ }^{84}$

La individualidad, en sentido antropológico, y la particularidad, en sentido lógico, están ligadas a lo que Hegel denomina la universalidad. Porque no hay todo sin partes, ni partes que no formen un todo en el que tienen inteligibilidad. El conjunto de las particularidades es una totalidad y la totalidad es el resultado de todas las relaciones particulares. No hay individuo sin un todo ni un todo sin individuos.

${ }^{82} \mathrm{~A}$ Hegel de inmediato se le considera como el modelo paradigmático del estatismo y como enemigo de la libertad, pero su filosofía no permite fácilmente este tipo de afirmaciones. El mismo Ludwig von Mises (1881-1973) lo advirtió en su obra Gobierno omnipotente. En nombre del Estado: "el estatismo, como antes el liberalismo, tuvo su origen en la Europa occidental y solo más tarde penetró en Alemania. Se ha dicho que las raíces autóctonas alemanas del estatismo podrían encontrarse en la utopía socialista de Fichte y en las enseñanzas sociológicas de Schelling y de Hegel. Sin embargo, las disertaciones de estos filósofos eran tan ajenas a los problemas y fines de la política social y económica, que no pudieron influir directamente en cuestiones políticas. No se ve qué uso podía derivar la política práctica de la afirmación de Hegel: 'el Estado es la realización de la idea ética. Es el espíritu ético en cuanto voluntad, manifiesta y revelada a sí misma, que se conoce y piensa a sí misma, y que realiza lo que sabe y en la medida en lo que sabe', o de su afirmación: 'el Estado es absolutamente racional en cuanto realización de la voluntad sustancial que posee en la particular conciencia de sí mismo una vez que la conciencia ha alcanzado su universalidad"'. Ludwig von Mises, Gobierno omnipotente. En nombre del Estado, 2002, Madrid, Unión Editorial, p. 77.

${ }^{83} \mathrm{G}$. W. Friedrich Hegel, Lecciones de la filosofia de la historia universal, 2008, Madrid, Gredos, trad. de José Gaos, p. 83.

${ }^{84}$ Ibid., p. 94. 
El Estado es una exigencia de la razón. ${ }^{85}$ Es la autoconciencia que tiene una comunidad y logra objetivarse en un conjunto de normas y de instituciones con poder soberano. Esta noción del Estado moderno se expresa en la definición lacónica de que el Estado es el ente abstracto de dominación política que reúne las tensiones de lo universal y lo particular y regula la vida de una comunidad. ${ }^{86}$ Para Hegel es perfectamente racional que las relaciones humanas se vuelvan objetivas en las instituciones y en las prácticas sociales. Por eso, pensar la existencia de un mercado sin el Estado es como imaginar la libertad abstracta sin ese orden social, jurídico, político y cultural en el que se realiza de manera efectiva ${ }^{87}$ El esfuerzo de concebir la existencia del Estado sin el mercado o del mercado sin el Estado, es para Hegel el fruto del entendimiento vacío. En ambos casos se trata de una idea que no corresponde con la realidad, porque la libertad no es valor ahistórico y abstracto, sino que es una realidad intersubjetiva: si soy efectivamente libre lo soy en relación con otros. Necesito a los otros para ser libre.

Para Hegel la libertad no solo es un concepto, sino una realidad histórica y cultural que se encuentra determinada por diversos ordenamientos jurídicos. El individuo no puede ejercer su libertad sino socialmente. Su libertad no sería sino una palabra si no está contemplada

104 en alguna norma. Suponer la existencia de un mercado sin Estado es ignorar que la libertad siempre se encuentra situada. El mercado es un aspecto central en vida de los hombres, pero no es la única esfera en la que los hombres desenvuelven su existencia. No obstante, eso no significa que se pueda afirmar el Estado sin el mercado. Negar el intercambio económico es negar la libertad individual y las posibilidades de desarrollo e inclusive de paz entre los hombres. Por eso podemos formularnos las siguientes preguntas: ¿Se puede hablar de un derecho humano al comercio y a participar libremente en el mercado? ¿Se puede hablar de un derecho al dinero ${ }^{88}$ ¿Qué relación existe entre derechos

${ }^{85} \mathrm{Cfr}$. G. W. Friedrich Hegel, Enciclopedia de las ciencias filosóficas, para uso de sus clases, 2010, Madrid, Alianza, trad. de Ramón Valls Plana, p. 551.

${ }^{86}$ Cfr.Principios de filosofía del derecho, p. 371.

${ }^{87}$ Enciclopedia de las ciencias filosóficas, para uso de sus clases, p. 550.

${ }^{88}$ Para el sociólogo alemán Niklas Luhmann (1927-1998), el dinero desplaza las necesidades del ser humano de la dependencia del tiempo y por la estructura económica de la 
humanos y economía? ¿Cómo debe ser la relación entre los derechos humanos y la empresa? ${ }^{89}$

Por eso, no debe ser extraño la existencia de organismos dedicados a la promoción del comercio, por ejemplo, la International Chamber of Comerce (ICC), ${ }^{90}$ que desde 1946 cuenta con el título de organismo consultivo de la Organización de las Naciones Unidas y está comprometido a promover todas las prácticas comerciales internacionales, en tanto que conducen a la prosperidad global y la paz. Quienes fundaron esta organización en 1919 se denominaron "mercaderes de la paz". La frase puede ser desconcertante, sobre todo si se piensa que el comercio puede ser causa de la injusticia, del deterioro ambiental y de la desigualdad, pero el intercambio es un acto social que permite el enriquecimiento mutuo y un medio indispensable para la prosperidad global y la paz entre las naciones. ${ }^{91}$

comunicación "la esfera total de los objetos (incluyendo la propiedad inmobiliaria) junto con el trabajo humano se monetariza. El dinero se convertirá en el símbolo por antonomasia de lo útil y toda relevancia económica se expresará en esencia como suma de dinero"; Luhmann, Los derechos fundamentales como institución. Aportación a la sociología política, 2010, México, Universidad Iberoamericana, p. 210. El dinero es la condición necesaria para la realización efectiva de los derechos fundamentales. Inclusive el "derecho a la propiedad": "no protege al particular en su personalidad ni en sus necesidades específicas ni le garantiza alimento [...] lo asegura en su función de participante en el sistema de comunicación de la economía, porque sin esa garantía el sistema de comunicación no se podría generalizar". Ibid., p. 219. El derecho a la propiedad tiene que ver con la capacidad que tiene el individuo para participar en el sistema económico: "poder disponer sobre dinero o sobre objetos valorados en dinero según sus posibilidades, precisadas a partir de reglas específicas y predecibles". Ibid., p. 222. Una persona que no tiene dinero no solo es pobre, sino que está excluida del sistema económico y de la sociedad. Difícilmente podrá ejercer algún derecho.

${ }^{89}$ John Gerard Ruggie, ¿Solamente negocio? Multinacionales y derechos humanos, 2014, Barcelona, Icaria, p. 123. Véase también el informe del representante especial del secretario general para la cuestión de los derechos humanos y las empresas transnacionales y otras empresas, John Ruggie, A/HRC/17/31 pp. 1-31.

${ }^{90}$ Véase $<$ https://iccwbo.org/>.

${ }^{91}$ En plena Segunda Guerra Mundial, Ludwig von Mises reflexionó tangencialmente sobre las relaciones entre el "comercio" y "la paz" en un artículo que publicó en la revista Cuadernos Americanos, después de impartir una serie de conferencias en la Ciudad de México. El artículo se titula "Ideas sobre la política de la posguerra" y en él se conmina a los hombres de Estado y a los economistas a reflexionar en el orden que requerirá el mundo cuando la guerra acabe. Según von Mises, ese orden mundial no puede fundarse en el nacionalismo económico. Así se expresa: "el proteccionismo [económico] no solo da lugar a desventajas económicas, sino que también imposibilita toda cooperación pacífica entre los Estados, conduciendo a una guerra segura. Si no lográsemos superar el nacionalismo económico, resultarían ilusorias todas nuestras 


\section{El Estado, el mercado y el totalitarismo}

Al inicio de esta exposición decíamos que a Hegel se le considera como el modelo paradigmático del "estatismo" y como "enemigo de la libertad", pero su filosofía no permite definitivamente este tipo de afirmaciones. Una exégesis rigurosa de las obras de Hegel impide estereotiparlo como un pensador totalitario. En realidad, la idea de un Estado o un régimen totalitario corresponde a un fenómeno político del siglo XX. La investigación de Hannah Arendt (1906-1975), Los orígenes del totalitarismo, devela que el origen del totalitarismo está ligado esencialmente a la sociedad de masas. De hecho, el término totalitario aplicado al campo de las doctrinas políticas se empezó a utilizar entre los enemigos del fascismo italiano de Benito Mussolini (1883-1945) hacia el año 1923 y significaba literalmente, dictadura.$^{92}$ A partir de este momento, la palabra totalitario se utiliza para describir las ideologías, movimientos y los regímenes políticos donde la libertad individual está seriamente restringida, especialmente en aquello en los que el Estado concentra todo el poder sin división, restricción y contrapeso. ${ }^{93}$ Miguel Villoro Toranzo (1920-1990) advierte que calificar a Hegel como totalitario es un error, en primer lugar, porque se trata de un anacronismo, puesto que el totalitarismo es un fenómeno que corresponde a la sociedad de masas del siglo xx, pero, sobre todo, porque un estudio del pensamiento de Hegel revela que no podría ser partidario del totalitarismo por su defensa de la libertad individual en el ámbito económico y político. ${ }^{94}$ Lo que sí es indiscutible es que sus ideas

esperanzas de lograr una reconstrucción de la cultura [...] todos los tópicos que se lanzan sobre las ventajas de la paz, sobre la cooperación internacional, sobre la creación de una sociedad de naciones y la reconstrucción de la economía mundial, no son sino frases huecas si se tiene la intención de conservar el proteccionismo". Ludwig von Mises, "Ideas sobre la política de la posguerra", Cuadernos Americanos, 4 (1942), pp. 88-89.

${ }^{92}$ Cfr. Raúl Morodo, “Totalitarismo”, en Elías Díaz y Alfonso Ruiz Miguel (comps.), Filosofia política II. Teoría del Estado, 1996, Madrid, Trotta, pp. 97-103.

${ }^{93}$ Hannah Arendt, Los orígenes del totalitarismo, 1998, Madrid, Taurus, pp. 279-314.

${ }^{94}$ Miguel Villoro Toranzo, La filosofia del derecho de G. W. F. Hegel, 2006, México, UNAM, pp. 13-15. 
y pensamientos se utilizaron indebidamente para justificar algunas posiciones totalitarias. ${ }^{95}$

Para Hegel, el Estado no puede concebirse como una unidad que elimina las diferencias, inclusive si se trata de aquellas que nacen del talento, la laboriosidad o la simple fortuna de los individuos. La "realidad efectiva" del Estado no puede ser la absoluta igualdad de sus miembros. Si bien en algunas circunstancias especiales cabe la intervención del Estado para brindar determinados niveles de bienestar a los ciudadanos, la vida económica no puede negar la libertad y el intercambio libre de las personas. ${ }^{96}$ Las personas y las corporaciones son las que tienen la obligación de organizarse para procurar, en la medida de sus posibilidades, el mayor bienestar para sí mismos. El bienestar es una tarea de la sociedad civil más que del Estado. ${ }^{97}$

Hegel no piensa que el Estado tenga como tarea primordial proveer el bienestar general de la población otorgando prestaciones ilimitadas a cada individuo. Hegel piensa que eso lesiona el sentido del honor y el valor de la propia autonomía del individuo. ${ }^{98}$ El Estado no debe ser el protagonista de la vida económica, sino que debe crear las condiciones para que se desarrollen libremente todas las particularidades. Si el Estado suple al mercado, el Estado pierde su razón de ser. Cada individuo o agrupación, al tomar sobre sí mismo su historia y su destino, favorece la riqueza del resto de la sociedad. Por eso, para Hegel, el

\footnotetext{
${ }^{95}$ Aunque Ludwig von Mises argumentó explícitamente que Hegel no podía ser culpado de totalitario, en la transcripción de una de sus Lecciones de 1951, para la Foundation for economic education, lo hace responsable de la formación de dos escuelas, la de "izquierda", que se convirtió en el marxismo, y la de "derecha", de la que proviene el nazismo. Esta posición se opone explícitamente a lo sostenido por él mismo en su obra Gobierno omnipotente y se acerca a la de Popper. Recordemos que ambos fueron fundadores de Mont Pelerin Society. De este modo se expresa von Mises: "La oposición a la libertad, la actitud marxiana, es típica de aquellos en el lado 'izquierdo' o 'progresista'. La gente se sorprende al saber que los llamados 'liberales' no están a favor de la libertad. Georg Wilhelm Friedrich Hegel [1770-1831], el famoso filósofo alemán, dio origen a dos escuelas: los hegelianos de 'izquierda' y los hegelianos de 'derecha'. Karl Marx [1818-1883] fue el más importante de los 'hegelianos de izquierda'. Los nazis vinieron de los 'hegelianos de derecha"'. Ludwig von Mises, The free market and its enemies: Pseudoscience, socialism, and inflation, 2004, Foundation for Economic Education, trad. al inglés de Bertina Bien Greaves, p. 5. La traducción al español es nuestra.

${ }^{96}$ Hegel, Principios de filosofía del derecho, p. 356.

${ }^{97}$ Ibid., pp. 365-366.

${ }^{98}$ Ibid., p. 359.
} 
Estado solo debe garantizar una atmósfera de libertad para que los individuos y las agrupaciones puedan llevar a cabo sus proyectos. Aunque lo pudiera hacer, el Estado no debe proveer el bienestar de sus ciudadanos, solo debe ocuparse de crear las condiciones para que cada miembro pueda participar a título personal o en sociedades intermedias. ${ }^{99}$

Si bien Hegel no se refiere explícitamente al "principio de subsidiariedad" y de "acción subsidiaria" formulado e introducido en las encíclicas papales Rerum Novarum (1891) de León XIII, y especialmente Quadragesimo Anno (1931) de Pío XI, su exposición de la "sociedad civil” y su relación con el Estado guarda ciertas similitudes. ${ }^{100}$ El término "subsidiariedad" se utiliza para designar el principio a partir del cual el Estado o cualquier institución ejecuta una labor orientada al "bien común", en especial, cuando advierte que los individuos o grupos particulares no la realizan adecuadamente, ya sea porque se encuentran impedidos para realizarla o por cualquier otro motivo. ${ }^{101}$ Este sería el significado positivo de la subsidiariedad según la cual el organismo responsable está obligado a brindar una prestación a una persona o comunidad. ${ }^{102}$ Por otro lado, la subsidiariedad demanda al Estado y sus autoridades abstenerse de intervenir allí donde las personas o las corporaciones estén en condición de bastarse por sí mismas. ${ }^{103}$ Solo sería prudente la inter-

${ }^{99}$ Loc. cit.

${ }^{100}$ La Academia Pontificia de las Ciencias Sociales convocó en 2017 a un seminario internacional para reflexionar sobre las relaciones de la economía con el orden social y político. El seminario se tituló "Cambiar las relaciones entre el mercado, el Estado y la sociedad civil". Las ponencias de este seminario se publicaron en dos tomos, de las que destacamos: Stefano Zamagni, "El vínculo de la lógica del mercado, el Estado y la sociedad civil en el magisterio", en Juan Carlos Scannone (comp.), Sociedad civil y bien común. Hacia una nueva articulación del mercado, El estado y la sociedad civil, 2018, Córdoba, Editorial de la Universidad Católica de Córdoba, vol. I, pp. 21-46.

${ }^{101}$ Cfr. Pontificio Consejo “justicia y paz”, Compendio de la doctrina social cristiana, 2005, Vaticano, Librería Editrice Vaticana, pp. 117-120.

${ }^{102}$ Cfr. Stefano Zamagni, "El bien común en la sociedad posmoderna: propuestas para la acción político-económica”, Revista Cultura Económica, 70 (2007), pp. 23-43.

${ }^{103}$ La subsidiariedad está entre las directrices más constantes de la doctrina social de la Iglesia. Si bien la formulación moderna se puede ubicar en el siglo XIX y XX, las ideas se encuentran presentes en Aristóteles y Santo Tomás de Aquino. Su origen moderno está vinculado a las reflexiones en torno al federalismo de Johannes Althusius (1557-1638). Cfr. Carlos J. McCadden M., "El principio de subsidiariedad y el tratado de Maastricht", Estudios, 30 (1992), pp. 93-105. 
vención del Estado para evitar que grandes masas de personas caigan por debajo de niveles de miseria y produzcan el desequilibrio social. ${ }^{104}$ La pobreza debería ser atendida cuando se ha extendido y tiene niveles que hacen insoportable la existencia. ${ }^{105}$ Sin embargo, Hegel piensa que el Estado no puede estar al servicio de una particularidad, de uno solo o varios agentes. Si esto ocurre, ya no se mira por el "bien de todos", ya no crea las condiciones para que todos puedan participar en el mercado. Hegel piensa que si el Estado se convierte en algo particular se pierde el vigor del todo, porque se debilitan las partes.

Existe otra interpretación defendida por Theodor Adorno (1903-1969) y Max Horkheimer (1895-1973) de la Escuela de Frankfurt, según la cual el totalitarismo no se origina en las formulaciones hegelianas, sino en todas las aspiraciones sistemáticas de la modernidad. Todo "sistema" es totalitario cuando pretende deducir al individuo particular de un solo postulado general. En su obra Dialéctica de la ilustración, los autores valoran el "trabajo de lo negativo" de Hegel, pero cuestionan el proyecto hegeliano porque, según ellos, al final esa negatividad queda superada en un sistema que la incluye: "En el concepto de negación determinada ha resaltado Hegel un elemento que distingue a la Ilustración [...] Pero al convertir finalmente en absoluto el resultado conocido del entero proceso de la negación, es decir, la totalidad en el sistema y en la historia, contravino la prohibición y cayó, él también, en mitología". ${ }^{106}$

La incomprensión del sistema hegeliano es la causa de que se malinterprete la relación de lo particular con lo absoluto y se piense erróneamente que se pierde el valor del individuo. Efectivamente, el totalitarismo es el modelo de un sistema de opresión en el que se anula toda diferencia pero no todo sistema es inmóvil ni cerrado. La Escuela de Frankfurt buscó demostrar que al nazismo, al comunismo soviético y

${ }^{104}$ Cfr. Hegel, Principios de filosofía del derecho, p. 359.

${ }^{105} C f r$. Petar Bojanić, "How to be together beyond corporations and firms? Hegel at the 'end of capitalism"”, Filozofija i drustvo, 28/ 3 (2017), pp. 563-578; Klaus Viewega, "Pobreza y riqueza. Derecho de socorro y derecho de resistencia en Hegel”, Estudios de Filosofía, 39 (2009), pp. 137-152.

${ }^{106}$ Theodor Adorno, Dialéctica de la ilustración. Fragmentos filosóficos, 1998, Madrid, Trotta, trad. de Juan José Sánchez, p. 78. 
al sistema capitalista estadounidense subyace la lógica de un sistema totalitario, no por ser hegelianos, sino porque estos sistemas se fundan en la racionalidad técnico-instrumental moderna. Son totalitarios en la medida en que un "sistema" se coloca por encima de la persona y esta queda reducida a una función utilitaria. En el totalitarismo, no solo se sustancializan las relaciones mutuas entre los hombres, sino que la dignidad de la persona queda subordinada al interés del sistema. ${ }^{107}$ Por eso, no se exagera si se dice que al contemplar el Estado sin mercado o al mercado sin Estado se está pensando totalitariamente. La parte se vuelve el todo en el que no caben las diferencias. Hegel precisamente se opuso a ello al justificar la unidad de las diferencias.

El mercado es central en vida de los hombres, pero no es la única esfera en la que los hombres desenvuelven su existencia. ${ }^{108}$ El mercado tiene leyes que deben ser reconocidas por el Estado para que este funcione, pero un mercado sin Estado es una quimera porque si bien el mercado tiene sus propias leyes, estas deben reconocerse y aplicarse con la fuerza del Estado. ${ }^{109}$ Además, el Estado no tiene solamente como tarea la vigilancia del buen funcionamiento del mercado, sino que debe velar por la libertad de los individuos en todos sus ámbitos. La dimensión económica no es la única en la que la persona desarrolla su vida.

La vida utilitaria, como dice Aristóteles, es un medio que permite a la persona ambicionar otros objetivos de carácter ético, estético, cultural o religioso. "Trabajamos con vistas al ocio", porque se trabaja para vivir y no se vive para trabajar. La persona se ocupa y se ata a sí misma en los negocios para tener tiempo libre y poder cultivar su humanidad. ${ }^{110}$

${ }^{107}$ Cfr. Nicolás María López Calera, Yo, el Estado. Bases para una teoría sustancializadora (no sustancialista) del Estado, 1992, Madrid, Trotta, pp.101-102.

${ }^{108}$ Cfr. Harry Hoefnagels, Introducción al pensar sociológico, 1967, Buenos Aires, Carlos Lohlé, trad. de José Rovira Armengol, pp. 173-186.

${ }^{109}$ Cfr. Ludwig von Mises, Gobierno omnipotente. En nombre del Estado, pp. 83-86; Joseph Stiglitz, Caída libre. El libre mercado y el hundimiento de la economía mundial, 2010, México, Santillana, trad. de Alejandro Pradera y Núria Petit, pp. 245-250.

${ }^{110}$ En eso estriba el cultivo de las humanidades en la educación. Las artes liberales como el conjunto de saberes cultivados por el hombre libre por oposición a las actividades serviles y que le permiten al hombre libre ser consciente de sí mismo, de las responsabilidades con su entorno cultural. La formación integral que Robert Hutchins describe de este modo: "Solo una educación concebida como crecimiento moral, intelectual, estético y espiritual puede 
El ocio es la actividad libre por medio de la cual una persona puede llegar a las proximidades de sí misma. El hombre liberado de la necesidad inmediata es intelectualmente libre para recrearse a sí mismo en la contemplación de la verdad y la belleza y en consecuencia, llevar una vida conforme a la sabiduría y el bien. ${ }^{11}$

La vida económica y la vida política son instrumentos valiosos para el desarrollo de la persona y de la sociedad, pero adquieren un sentido totalitario cuando esos sistemas se vuelven un fin en sí mismo y subordinan la vida contemplativa, la razón y el quehacer humanos a una sola de sus dimensiones: la que parece obsesionada con la producción ilimitada, la tecnificación de la razón y de lo humano. Ese totalitarismo de la tecnificación es al que se opone Hegel, porque oscurece el sentido de la libertad, la solidaridad y la persona humana.

realizar esos objetivos". La universidad de utopía, 1968, Buenos Aires, Eudeba, trad. de Noemí Rosenblatt, pp. 16-17.

${ }^{111}$ Para Josef Pieper, el "ocio" es uno de los fundamentos de la cultura occidental. El ocio no significa pasividad, inactividad o pereza, sino que de acuerdo con su origen etimológico, el vocablo griego $\sigma \chi 0 \lambda \hat{~ s e ~ r e f i e r e ~ a ~ u n ~ t i p o ~ d e ~ a c t i v i d a d ~ l i b r e, ~ n o ~ u t i l i t a r i a, ~ q u e ~ n i e g a ~ e l ~ o c i o ~}$ (neg-ocio) y de la que deriva el término latino de schola, escuela y scholaris, escolar. Cfr. Josef Pieper, El ocio y la vida intelectual, 1979, Madrid, Rialp, pp. 11-16. 
Se prohíbe su reproducción total o parcial por cualquier medio, incluido electrónico, sin permiso previo y por escrito de los editores. 